\title{
Platelet Microparticles and miRNA Transfer in Cancer Progression: Many Targets, Modes of Action, and Effects Across Cancer Stages
}

\section{OPEN ACCESS}

Edited by:

Wai Ho Tang,

Guangzhou Women and Children

Medical Center, China

Reviewed by:

Shizuka Uchida,

Cardiovascular Innovation Institute

(CII), United States

Jeonga Kim,

University of Alabama at Birmingham,

United States

${ }^{*}$ Correspondence:

Lawrence E. Goldfinger goldfinger@temple.edu

Specialty section:

This article was submitted to Cardiovascular Metabolism,

a section of the journal

Frontiers in Cardiovascular Medicine

Received: 18 December 2017

Accepted: 12 February 2018

Published: 28 February 2018

Citation:

Lazar S and Goldfinger LE

(2018) Platelet Microparticles and miRNA Transfer in Cancer

Progression: Many Targets, Modes of

Action, and Effects Across Cancer

Stages.

Front. Cardiovasc. Med. 5:13. doi: $10.3389 / f c v m .2018 .00013$

\author{
Sophia Lazar ${ }^{1,2}$ and Lawrence E. Goldfinger ${ }^{1,2 *}$ \\ ${ }^{1}$ The Sol Sherry Thrombosis Research Center, Department of Anatomy and Cell Biology, Lewis Katz School of Medicine, \\ Temple University, Philadelphia, PA, United States, ${ }^{2}$ Cancer Biology Program, Fox Chase Cancer Center, Philadelphia, PA, \\ United States
}

Platelet-derived microparticles (PMPs) have long been known to increase in circulation in the presence of cancer, and have been considered to be cancer promoting by multiple mechanisms including shrouding of circulating tumor cells allowing immune evasion, inducing a procoagulant state associated with increased risk for venous thromboembolic events in cancer patients, and supporting metastatic dissemination by establishment of niches for anchorage of circulating tumor cells. These modes of PMP-enhanced progression of late stage cancer are generally based on the adhesive and procoagulant surfaces of PMPs. However, it is now clear that PMPs can also act as intercellular signaling vesicles, by fusion with target cells and transfer of a broad array of plateletderived molecular contents including growth factors, angiogenic modulators, second messengers, lipids, and nucleic acids. It is also now well established that PMPs are major repositories of microRNAs (miRNAs). In recent years, new roles of PMPs in cancer have begun emerging, primarily reflecting their ability to transfer miRNA contents and modulate gene expression in target cells, allowing PMPs to affect cancer development at many stages. PMPs have been shown to interact with and transfer miRNAs to various blood vascular cells including endothelium, macrophages and neutrophils. As each of these contributes to cancer progression, PMP-mediated miRNA transfer can affect immune response, NETosis, tumor angiogenesis, and likely other cancer-associated processes. Recently, PMP miRNA transfer was found to suppress primary tumor growth, via PMP infiltration in solid tumors, anchorage to tumor cells and direct miRNA transfer, resulting in tumor cell gene suppression and inhibition of tumor growth. This mini-review will summarize current knowledge of PMP-miRNA interactions with cancer-associated cells and effects in cancer progression, and will indicate new research directions for understanding platelet-cancer interactions. 


\section{INTRODUCTION}

Platelets, which are derived from megakaryocytes, are blood-borne cell fragments that are the primary cellular agents in hemostasis and thrombosis. Vascular injury or thrombogenic stimuli activate platelet receptors, promoting platelet granule secretion, coagulation, and platelet crosslinking of fibrin leading to thrombus formation (1). Activated platelets also release platelet-derived microparticles (PMPs): extracellular vesicles formed by outward blebbing of the platelet plasma membrane followed by scission, trapping platelet-derived cytosolic material, which account for up to $90 \%$ of circulating microparticles (MPs) (2). The adhesive and pro-coagulant nature of PMPs, due to their surface expression of phosphatidylserine (PS) and other platelet antigens, contributes to the prothrombotic state often associated with pathologies which display increased levels of circulating PMPs, including cancer (3). PMPs also play important roles in long-range cell-tocell communication as they contain many of the same proteins, lipids, and oligonucleotides as their platelet progenitors. In particular, PMPs are enriched in microRNAs (miRNAs) derived from circulating platelets (4). MiRNAs are small non-coding RNAs that suppress mRNA translation through multiple mechanisms. Within the nucleus of megakaryocytes, long primary RNAs harboring tandem miRNAs transcribed by RNA polymerase II are processed by Drosha and DGCR8 into short hairpin premiRNAs, which are subsequently exported to the cytoplasm (5). These cytoplasmic pre-miRNAs are inherited by maturing platelets along with Dicer1, the endonuclease responsible for generation hairpin cleavage to generate mature miRNA, consisting of an approximately $22 \mathrm{nt}$ long RNA duplex; thus, platelets are enriched in pre-miRNAs and mature miRNAs (6-8). These platelet-derived miRNAs are packaged into PMPs and constitute a major fraction of the platelet content released in PMPS (9). PMPs have long been known to increase in circulation in cancer patients (10), which has been associated with poor cancer prognosis (11). However, our understanding of the PMP-cancer axis is still evolving; it is now clear that PMPs and their entrapped miRNAs also have tumor suppressive roles, as we have recently found with respect to growth of primary solid tumors (12). Thus, the roles of PMPs and platelet miRNAs in cancer progression are multi-faceted and not yet completely understood.

\section{Cancer-Promoting Roles of PMPs}

Activated platelets, as well as PMPs, are known to play important roles in cancer progression. The presence of cancer also promotes platelet activation, creating the so-called platelet-cancer loop. Indeed, cancer patients are at increased risk for platelet-driven venous thromboembolism, which is a significant contributor to morbidity and mortality in cancer patients, depending on tissue type; pancreatic and lung cancer patients are at especially high risk (13). This prothrombotic state in cancer is due not only to increased platelet activation, but also to the concomitant increase in PS-positive PMPs which further enhance coagulation $(11,14)$. Increases in circulating PMPs vary by cancer type but generally appear to increase with advanced cancer stage. For example, PMP levels in patients with myeloproliferative neoplasms were roughly doubled compared to healthy subjects, up to four times in colorectal and oral cancer patients, as high as 10 times higher in breast cancer, and up to 35 times higher in stage IV gastic cancer; in each cohort the highest levels were found in advanced stage cancer and in most cases were associated with the presence of distal metastases (15-19). Platelets can shroud blood-borne tumor cells, protecting them from immune detection (20), suggesting that PMPs may play a similar role. This tumor-shrouding property of platelets may also be supported by PMPs, as PMP membranes contain the same proteins as platelet surfaces. However, further studies are needed to determine if PMPs truly act in this fashion to promote cancer development.

Though platelets have long been known to play a key role in metastatic dissemination, involvement of PMPs, through multiple mechanisms, has only recently been shown. Matrix metalloproteinases (MMPs) are the principal enzymes involved in degradation of the extracellular matrix (ECM), preceding both intravasation and angiogenesis (21). PMPs have been shown to promote secretion of MMP-2, specifically in prostate cancer cells, thereby promoting vessel invasion (22). A similar role for PMPs has been demonstrated with lung cancer cells in vitro, where PMPs were shown to transfer integrin CD41 to cancer cells as well as to promote surface expression of membrane type 1-MMPs (23). Interestingly, the same study also reported that PMP-associated Lewis Lung Carcinoma cells produced tumor foci with increased metastatic potential, indicating the pro-metastatic nature of these molecules (23). In addition, the pro-coagulant surface of PMPs facilitates docking of metastatic tumor cells to distal sites, thereby facilitating establishment of new nodes $(24,25)$; this may go a long way to explain the correlation between increased PMPs and poor prognosis in cancer.

Both platelets and PMPs have also been shown to play roles in neoangiogenesis, a process required for both growth of primary solid tumors and metastasis. PMPs promote endothelial proliferation in vitro, due in part to their lipid components and surface receptors (26). The ability of PMPs to prompt an angiogenic response both in vitro and in vivo has been attributed to their harboring cytokines such as vascular endothelial growth factor (VEGF), basic fibroblast growth factor, and plateletderived growth factor (27). Alternatively, PMPs may exert their pro-angiogenic effects by binding a variety of signaling molecules including tissue factor (TF), platelet-activating factor, and VEGF (28). While is it now clear that PMPs are intimately tied to both metastatic dissemination of tumor cells and angiogenesis, tumor angiogenesis has not been thoroughly explored in this context; moreover, these effects have been primarily attributed to the surface properties of PMPs, and thus putative roles of their cargo have yet to be elucidated.

\section{PMPs as Intercellular Signaling Vesicles}

PMPs encapsulate growth factors, angiogenic modulators, and nucleic acids derived from platelets (29). Importantly, PMPs also contain platelet-derived bioactive molecules, such as sphingosine 1-phosphate (S1P) and arachidonic acid (AA) (30). Due to their small size, ability to travel long distances through 
TABLE 1 | PMP-encapsulated miRNAs and associated roles in cancer

\begin{tabular}{llll}
\hline miRNA & Role & Cell Type & Reference \\
\hline miR-223 & $\begin{array}{l}\text { Suppression of FBXW7 and } \\
\text { EFNA1, possibly resulting in } \\
\text { apoptosis }\end{array}$ & $\begin{array}{l}\text { HUVEC } \\
\text { (endothelial) }\end{array}$ & $(9,36)$ \\
miR-223 & $\begin{array}{l}\text { Suppression of EPB41L3, leading } \\
\text { to increased invasiveness }\end{array}$ & $\begin{array}{l}\text { Lung cancer } \\
\text { cells }\end{array}$ & $(37)$ \\
miR-126-3p & $\begin{array}{l}\text { Increased phagocytic phenotype } \\
\text { Primary human }\end{array}$ & (38) \\
miR-183 & $\begin{array}{l}\text { Suppress natural killer cell } \\
\text { activation, possibly via silencing } \\
\text { of DAP12 }\end{array}$ & $\begin{array}{l}\text { Natural killer } \\
\text { cells }\end{array}$ & $(39,40)$ \\
miR-24 & $\begin{array}{l}\text { Mitochondrial dysfunction and } \\
\text { tumor cell apoptosis, leading to } \\
\text { suppression of tumor growth }\end{array}$ & $\begin{array}{l}\text { Lung and colon } \\
\text { cancer cells }\end{array}$ & $(12)$ \\
& & &
\end{tabular}

miRNAs transferred from PMPs to cancer-associated cells are shown, with target cell type and cellular effects.

the blood stream, and capacity to fuse with or be internalized by target cells, PMPs have been proposed to play important physiological roles as intercellular signaling vesicles (30). Specific effects of molecular transfer via PMPs may be dependent on target cell type; for example, PMP exposure can variably suppress mitotic and migration signaling genes in endothelial cells, promote adhesion and proliferation of some normal and transformed blood cells such as increasing monocyteendothelial interaction, or induce chemotactic motility of monocytes $(9,29,31,32)$.

Circulating PMPs are enriched in miRNAs (33), which are conserved and potent regulators of gene expression. Importantly, miRNA content of PMPs appears to constitute subsets of miRNA cohorts in platelets, indicating that miRNAs are actively selected and packaged into PMPs for secretion rather than stochastically incorporated (34). Analysis of patient samples has shown that circulating PMP miRNA content is altered during various pathologies, implying they may function as potential biomarkers for disease as well as platelet activation $(34,35)$. Purified PMPs can transfer their miRNAs to recipient cells, with particular physiological effects tied to transport of specific miRNAs to distinct cell types. A summary of known PMP-encapsulated miRNAs transferred to different cell types involved in cancer and established or putative effects is listed in Table 1. For example, PMPs released following thrombin activation of platelets are enriched in miR-223. Internalization of PMPs by human umbilical vein endothelial cells (HUVEC), and subsequent transfer of Argonaute 2 (Ago2) - miR-223 complexes results in downregulation of gene expression for targets of miR-223 within the recipient endothelial cells, which in some cases may lead to endothelial apoptosis $(9,36)$. In contrast, PMPmediated transfer of the same miRNA to lung cancer cells increases cancer invasiveness by suppression of EPB41L3, a known tumor suppressor (37). Whether these distinctions reflect biased selection of gene targets of particular miRNAs is not clear; next generation sequencing for RNA expression and expanded mapping of miRNA targets is needed to elucidate the full scope of platelet miRNA effects.

\section{Interactions of PMPs with Blood Vascular Cells and Potential Roles in Cancer}

PMPs have been shown to interact with many types of blood vascular cells, including circulating tumor cells, leukocytes, and endothelium. Each of these interactions, coupled with PMPmediated transfer of miRNAs, may affect functions of the target cells during cancer progression. For example, the effects of transfer of miR-223 to endothelium (9) on tumor angiogenesis has not been investigated. Moreover, other miRNAs are known to be transferred from PMPs to endothelial cells; these have yet to be fully characterized, their mRNA targets have not been identified, and functional outcomes with respect to tumor angiogenesis are still unknown.

PMPs themselves have been shown to be pro-inflammatory, triggering cytokine responses via interleukin-1 signaling. This signaling response appears to be specific to PMPs released from platelets activated via the glycoprotein VI (GPVI) collagen receptor complex, suggesting that PMPs produced following activation of GPVI - typically as a result of vascular damage - may contain a subset of miRNAs specialized to induce such a response (41). However, it is likely that other platelet agonists, and platelet hyperactivation generally, contributes to a pro-inflammatory state in cancer; whether this effect aids in immune anti-tumor function remains to be determined. Additionally, PMPs have been shown to interact with monocytes and modify both macrophage and dendritic cell differentiation, implying that PMPs are able to actively modulate the immune response and regulate inflammation (42). However, the exact mechanisms of these interactions are still unknown.

PMPs released by apoptotic platelets, differing to some degree from those deriving from activated platelets, have been shown to promote monocyte differentiation to M2 macrophages, monocytederived phagocytic white cells often found at areas of immune activation (43). More recently it has been shown that primary human macrophages are able to internalize PMPs, a process that delivers functional miR-126-3p, which is then able to alter gene expression and lead to a more phagocytic phenotype (38). It will be very interesting to observe how PMP-miRNA stimulation of this phagocytic phenotype relates to the presence, activity, and tumor growth effects of tumor-associated macrophages. Similarly, PMPs can interact with and suppress function of natural killer (NK) cells - innate immune lymphocytes that attack transformed cells - via suppression of NK activation adapter DAP12, through mechanisms that may include transfer of platelet-derived miR-183 (39). This effect is particularly intriguing as miR-183-mediated knockdown of DAP12 suppresses cytolytic function in tumor-associated NK cells (40); it is tempting to speculate that PMPs may act as major catalysts in this process.

PMPs have the capacity to interact with neutrophils, phagocytic granular immune cells, and PMPS mediate interactions between neutrophils with other leukocytes (44), in part due to PMP surface expression of platelet receptors. Glycoprotein Ib (GPIb) receptor, present on the surface of PMPs, interacting with Mac-1 ligands on leukocytes, supports PMP-neutrophil interaction and neutrophil activation (45). PMPs are also able to transfer glycoprotein IIb/IIIa (GPIIb/IIIa) receptors to neutrophils both following isolation and in whole blood (46). It has been suggested that the 
transferred GPIIb/IIIA receptors are able to participate in NFkB activation of human neutrophils (46). Internalization of PMPs by neutrophils has been shown to be highly regulated, and to be stimulated during autoimmune inflammatory arthritis due to the presence of 12-lipoxygenase and phospholipase A2-IIA $(47,48)$. Though activated platelets have been shown to stimulate type I interferon production, NETosis by neutrophils, and activation of dendritic cells and T and B lymphocytes (49), it is not yet know if these effects are mediated via PMP release. Neutrophils are intimately involved in cancer progression, via the above effects but also due to their ability to infiltrate tumors and potentially exert anti-tumor effects. However, tumor-associated neutrophils are, like platelets and PMPs, associated with poor cancer prognosis (50). As with PMP-miRNA-monocyte/macrophage interactions, effects of PMP-miRNAs on neutrophil roles in cancer are only just beginning to be explored.

\section{Cancer-Suppressive Roles of PMP- miRNAs}

While PMPs have historically been viewed as cancer promoting, their ability to transfer miRNA and downregulate gene expression in various cell types suggests that PMPs themselves could have tumorsuppressive roles. Our group recently found that PMPs selectively infiltrate solid tumors, potentially as a result of the enhanced permeation and retention, and PMPs transfer platelet miRNAs to the tumor cells, with tumor suppressive effects in vitro and in vivo across multiple tumor types (12). PMP-mediated miRNA transfer was associated with tumor cell apoptosis, with platelet-derived miR-24 identified as a key miRNA. RNA targets of PMP-transferred miR24 include mitochondrial $m t-\mathrm{Nd} 2$, and miRNA transfer resulted in mitochondrial dysfunction and suppression of tumor growth in a miR-24-dependent manner in lung and colon cancer cells in vitro and in vivo (12). This mechanism of PMP-miRNA-mediated gene regulation and tumor growth suppression requires further exploration. The mechanisms of PMP tumor infiltration, anchorage to tumor cells, and miRNA transfer, as well as the cohort of transferred miRNAs and global effects on tumor cell gene expression, remain to be fully investigated. Nonetheless, it now appears that platelets themselves may be principally cancer-promoting, while tumor-infiltrating PMPs act as a counterbalance, suppressing cancer development of, at least, primary solid tumors (51).

\section{CONCLUSIONS}

The interplay between PMPs, platelet miRNAs and cancer progression is elaborate and multifaceted. On the one hand, many of the platelet-like qualities of PMPs, such as their shared expression of surface antigens, promote cancer progression. Platelets themselves have been shown to promote cancer through

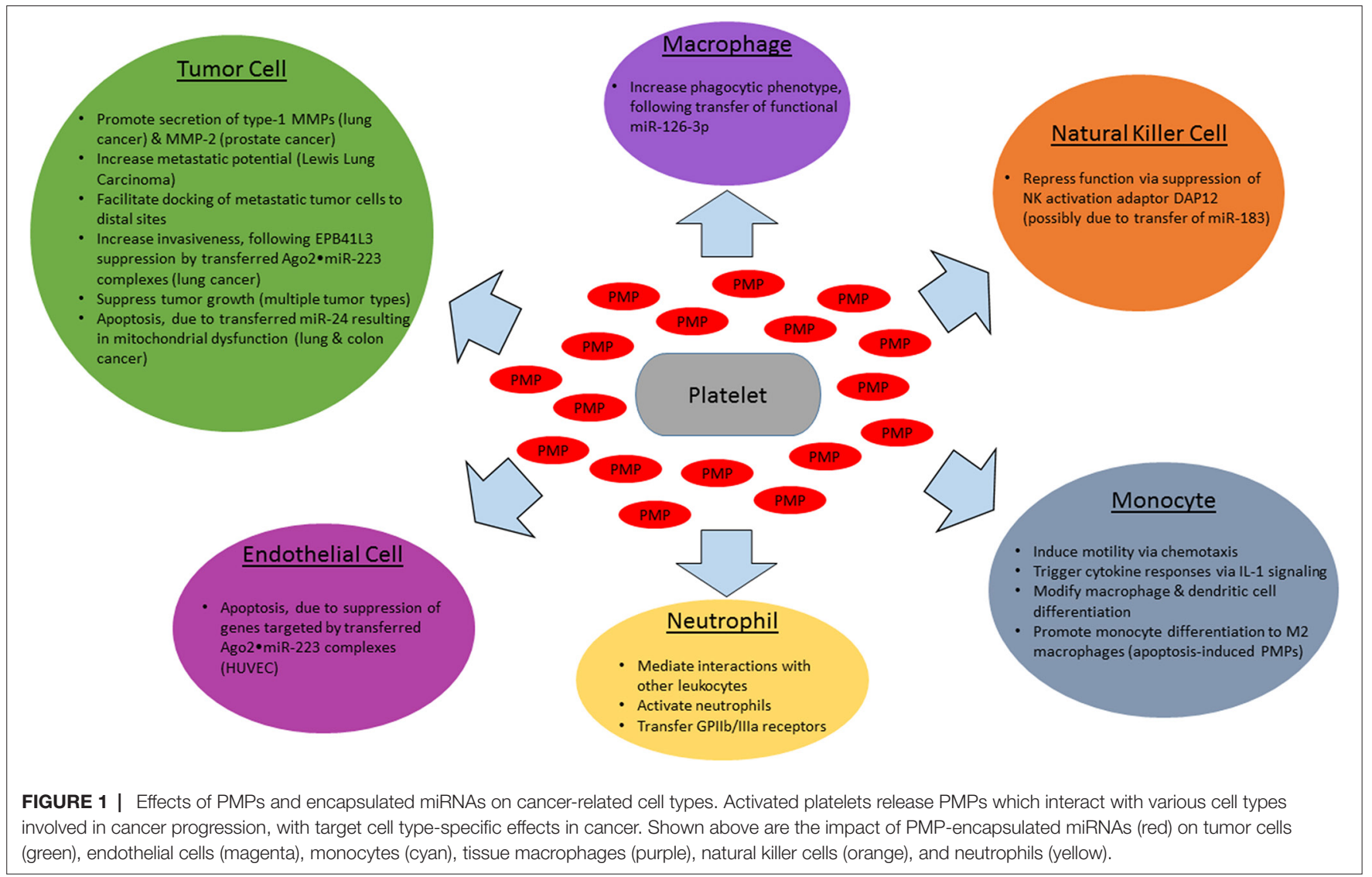


a variety of mechanisms, yet similar actions of PMPs are still unfolding. Questions regarding PMP involvement in circulating tumor cell immune evasion and metastatic dissemination remain unanswered. In parallel, PMPs were recently shown to mediate horizontal RNA transfer, adding yet another layer of complexity. As PMPs are able to directly inhibit tumor growth, it is possible that platelets and PMPs compensate for one another in regards to their immediate impact on tumor cells themselves, with platelets stimulating and PMPs inhibiting cancer progression. Conversely, transfer of platelet miRNAs via PMPs to other cell types, such as immune cells, appears to indirectly promote cancer. Available data suggest dual-phase effects, wherein PMPs have antineoplastic roles in primary tumor growth through miRNA transfer, but PMPs support cancer progression at later stages through mostly miRNAindependent mechanisms. Much further research is needed to fully elucidate the ways in which platelets and PMPs both interact with tumor cells and modulate cancer progression.

As it is now clear that PMPs are able to function as signaling vesicles, relaying regulatory miRNAs to a diverse assortment of cell types, a great deal remains to be determined with respect to effects on cancer progression (Figure 1). Specific miRNAs and their mRNA targets have yet to be identified for a majority of tumor cell

\section{REFERENCES}

1. Born GU, Rotman A. Platelets in hemostasis and thrombosis. In: Platelets: cellular response mechanism and their biological significance. New York: Wiley Interscience (1980). p. 3-17.

2. Orozco AF, Lewis DE. Flow cytometric analysis of circulating microparticles in plasma. Cytometry A (2010) 77(6):502-14. doi: 10.1002/cyto.a.20886

3. Zhao L, Bi Y, Kou J, Shi J, Piao D. Phosphatidylserine exposing-platelets and microparticles promote procoagulant activity in colon cancer patients. J Exp Clin Cancer Res (2016) 35:54. doi: 10.1186/s13046-016-0328-9

4. Weyrich AS, Schwertz H, Kraiss LW, Zimmerman GA. Protein synthesis by platelets: historical and new perspectives. J Thromb Haemost (2009) 7(2):2416. doi: 10.1111/j.1538-7836.2008.03211.x

5. He L, Hannon GJ. MicroRNAs: small RNAs with a big role in gene regulation. Nat Rev Genet (2004) 5(7):522-31. doi: 10.1038/nrg1379

6. Landry P, Plante I, Ouellet DL, Perron MP, Rousseau G, Provost P. Existence of a microRNA pathway in anucleate platelets. Nat Struct Mol Biol (2009) 16(9):961-6. doi: 10.1038/nsmb.1651

7. Plé H, Landry P, Benham A, Coarfa C, Gunaratne PH, Provost P. The repertoire and features of human platelet microRNAs. PLoS ONE (2012) 7(12):e50746. doi: 10.1371/journal.pone.0050746

8. Rowley JW, Chappaz S, Corduan A, Chong MM, Campbell R, Khoury A, et al. Dicer1-mediated miRNA processing shapes the mRNA profile and function of murine platelets. Blood (2016) 127(14):1743-51. doi: 10.1182/blood-2015-07661371

9. Laffont B, Corduan A, Plé H, Duchez AC, Cloutier N, Boilard E, et al. Activated platelets can deliver mRNA regulatory Ago2*microRNA complexes to endothelial cells via microparticles. Blood (2013) 122(2):253-61. doi: 10.1182/ blood-2013-03-492801

10. Italiano JE, Mairuhu AT, Flaumenhaft R. Clinical relevance of microparticles from platelets and megakaryocytes. Curr Opin Hematol (2010) 17(6):578-84. doi: 10.1097/MOH.0b013e32833e77ee

11. Mezouar S, Mege D, Darbousset R, Farge D, Debourdeau P, Dignat-George $\mathrm{F}$, et al. Involvement of platelet-derived microparticles in tumor progression and thrombosis. Semin Oncol (2014) 41(3):346-58. doi: 10.1053/j. seminoncol.2014.04.010

12. Michael JV, Wurtzel JGT, Mao GF, Rao AK, Kolpakov MA, Sabri A, et al. Platelet microparticles infiltrating solid tumors transfer miRNAs that suppress types, and phenotypic outcomes of mRNA silencing may differ by tumor type. The narrative is even further complicated by PMPmediated miRNA transfer to vascular cells. Overall, circulating PMPs and the regulatory platelet-derived miRNAs found within them play important roles across many stages of cancer. Elucidating these mechanisms will be of great interest and will reveal potential hot spots for cancer therapeutic targeting.

\section{AUTHOR CONTRIBUTIONS}

SL and LG wrote and edited the manuscript.

\section{FUNDING}

This work was supported by NIH grant R01HL137207 to LG.

\section{ACKNOWLEDGEMENT}

We thank Jeremy GT Wurtzel for critical reading of the manuscript. tumor growth. Blood (2017) 130(5):567-80. doi: 10.1182/blood-2016-11751099

13. Hisada Y, Mackman N. Cancer-associated pathways and biomarkers of venous thrombosis. Blood (2017) 130(13):1499-506. doi: 10.1182/blood-2017-03743211

14. Rao AK, Rao DA. Platelets signal and tumors take off. Blood (2012) 120(24):4667-8. doi: 10.1182/blood-2012-09-457325

15. Chaari M, Ayadi I, Rousseau A, Lefkou E, van Dreden P, Sidibe F, et al. Impact of breast cancer stage, time from diagnosis and chemotherapy on plasma and cellular biomarkers of hypercoagulability. BMC Cancer (2014) 14:991. doi: 10.1186/1471-2407-14-991

16. Dymicka-Piekarska V, Gryko M, Lipska A, Korniluk A, Siergiejko E, Kemona H. Platelet-derived microparticles in patients with colorectal cancer. J Cancer Ther (2012) 03(06):898-901. doi: 10.4236/jct.2012.326115

17. Kim HK, Song KS, Park YS, Kang YH, Lee YJ, Lee KR, et al. Elevated levels of circulating platelet microparticles, VEGF, IL-6 and RANTES in patients with gastric cancer: possible role of a metastasis predictor. Eur J Cancer (2003) 39(2):184-91. doi: 10.1016/S0959-8049(02)00596-8

18. Ren JG, Man QW, Zhang W, Li C, Xiong XP, Zhu JY, et al. Elevated level of circulating platelet-derived microparticles in oral cancer. J Dent Res (2016) 95(1):87-93. doi: 10.1177/0022034515592593

19. Zhang W, Qi J, Zhao S, Shen W, Dai L, Han W, et al. Clinical significance of circulating microparticles in $\mathrm{Ph}$ - myeloproliferative neoplasms. Oncol Lett (2017) 14(2):2531-6. doi: 10.3892/ol.2017.6459

20. Bambace NM, Holmes CE. The platelet contribution to cancer progression. J Thromb Haemost (2011) 9(2):237-49. doi: 10.1111/j.1538-7836.2010.04131.x

21. Gialeli C, Theocharis AD, Karamanos NK. Roles of matrix metalloproteinases in cancer progression and their pharmacological targeting. Febs J (2011) 278(1):16-27. doi: 10.1111/j.1742-4658.2010.07919.x

22. Dashevsky O, Varon D, Brill A. Platelet-derived microparticles promote invasiveness of prostate cancer cells via upregulation of MMP-2 production. Int J Cancer (2009) 124(8):1773-7. doi: 10.1002/ijc.24016

23. Janowska-Wieczorek A, Wysoczynski M, Kijowski J, Marquez-Curtis L, Machalinski B, Ratajczak J, et al. Microvesicles derived from activated platelets induce metastasis and angiogenesis in lung cancer. Int J Cancer (2005) 113(5):752-60. doi: 10.1002/ijc.20657

24. Labelle M, Begum S, Hynes RO. Platelets guide the formation of early metastatic niches. Proc Natl Acad Sci U.S.A (2014) 111(30):E3053-3061. doi: $10.1073 /$ pnas. 1411082111 
25. Varon D, Hayon Y, Dashevsky O, Shai E. Involvement of platelet derived microparticles in tumor metastasis and tissue regeneration. Thromb. Res. (2012) 130(Suppl 1):S98-99. doi: 10.1016/j.thromres.2012.08.289

26. Kim HK, Song KS, Chung JH, Lee KR, Lee SN. Platelet microparticles induce angiogenesis in vitro. Br J Haematol (2004) 124(3):376-84. doi: 10.1046/j.13652141.2003.04773.x

27. Brill A, Dashevsky O, Rivo J, Gozal Y, Varon D. Platelet-derived microparticles induce angiogenesis and stimulate post-ischemic revascularization. Cardiovasc Res (2005) 67(1):30-8. doi: 10.1016/j.cardiores.2005.04.007

28. Horstman LL, Jy W, Minagar A, Bidot CJ, Jimenez JJ, Alexander JS, et al. Cellderived microparticles and exosomes in neuroinflammatory disorders. Int Rev Neurobiol (2007) 79:227-68. doi: 10.1016/S0074-7742(07)79010-4

29. Żmigrodzka M, Guzera M, Miśkiewicz A, Jagielski D, Winnicka A. The biology of extracellular vesicles with focus on platelet microparticles and their role in cancer development and progression. Tumour Biol (2016) 37(11):14391-401. doi: 10.1007/s13277-016-5358-6

30. Ratajczak J, Wysoczynski M, Hayek F, Janowska-Wieczorek A, Ratajczak MZ. Membrane-derived microvesicles: important and underappreciated mediators of cell-to-cell communication. Leukemia (2006) 20(9):1487-95. doi: 10.1038/ sj.leu. 2404296

31. Barry OP, Praticò D, Savani RC, Fitzgerald GA. Modulation of monocyteendothelial cell interactions by platelet microparticles. J Clin Invest (1998) 102(1):136-44. doi: 10.1172/JCI2592

32. Lin HC, Chang HW, Hsiao SH, Chou ML, Seghatchian J, Burnouf T. Plateletderived microparticles trigger THP-1 monocytic cell aggregation and release of pro-coagulant tissue factor-expressing microparticles in vitro. Transfus Apher Sci (2015) 53(2):246-52. doi: 10.1016/j.transci.2015.10.002

33. Hunter MP, Ismail N, Zhang X, Aguda BD, Lee EJ, Yu L, et al. Detection of microRNA expression in human peripheral blood microvesicles. PLoS ONE (2008) 3(11):e3694. doi: 10.1371/journal.pone.0003694

34. Diehl P, Fricke A, Sander L, Stamm J, Bassler N, Htun N, et al. Microparticles: major transport vehicles for distinct microRNAs in circulation. Cardiovasc Res (2012) 93(4):633-44. doi: 10.1093/cvr/cvs007

35. Willeit P, Zampetaki A, Dudek K, Kaudewitz D, King A, Kirkby NS, et al. Circulating microRNAs as novel biomarkers for platelet activation. Circ Res (2013) 112(4):595-600. doi: 10.1161/CIRCRESAHA.111.300539

36. Pan Y, Liang H, Liu H, Li D, Chen X, Li L, et al. Platelet-secreted microRNA-223 promotes endothelial cell apoptosis induced by advanced glycation end products via targeting the insulin-like growth factor 1 receptor. I Immunol (2014) 192(1):437-46. doi: 10.4049/jimmunol.1301790

37. Liang H, Yan X, Pan Y, Wang Y, Wang N, Li L, et al. MicroRNA-223 delivered by platelet-derived microvesicles promotes lung cancer cell invasion via targeting tumor suppressor EPB41L3. Mol Cancer (2015) 14:58. doi: 10.1186/ s12943-015-0327-z

38. Laffont B, Corduan A, Rousseau M, Duchez AC, Lee CH, Boilard E, et al. Platelet microparticles reprogram macrophage gene expression and function. Thromb Haemost (2016) 115(2):311-23. doi: 10.1160/TH15-05-0389

39. Sadallah S, Schmied L, Eken C, Charoudeh HN, Amicarella F, Schifferli JA. Platelet-derived ectosomes reduce NK cell function. J Immunol (2016) 197(5):1663-71. doi: 10.4049/jimmunol.1502658
40. Donatelli SS, Zhou JM, Gilvary DL, Eksioglu EA, Chen X, Cress WD, et al. TGF- $\beta$-inducible microRNA-183 silences tumor-associated natural killer cells. Proc Natl Acad Sci USA (2014) 111(11):4203-8. doi: 10.1073/pnas.1319269111

41. Boilard E, Nigrovic PA, Larabee K, Watts GF, Coblyn JS, Weinblatt ME, et al. Platelets amplify inflammation in arthritis via collagen-dependent microparticle production. Science (2010) 327(5965):580-3. doi: 10.1126/ science. 1181928

42. Sadallah S, Eken C, Martin PJ, Schifferli JA. Microparticles (ectosomes) shed by stored human platelets downregulate macrophages and modify the development of dendritic cells. J Immunol (2011) 186(11):6543-52. doi: 10.4049/jimmunol.1002788

43. Vasina EM, Cauwenberghs S, Feijge MA, Heemskerk JW, Weber C, Koenen RR. Microparticles from apoptotic platelets promote resident macrophage differentiation. Cell Death Dis (2011) 2:e211. doi: 10.1038/cddis.2011.94

44. Forlow SB, Mcever RP, Nollert MU. Leukocyte-leukocyte interactions mediated by platelet microparticles under flow. Blood (2000) 95(4):1317-23.

45. Lo SC, Hung CY, Lin DT, Peng HC, Huang TF. Involvement of platelet glycoprotein $\mathrm{Ib}$ in platelet microparticle mediated neutrophil activation. $J$ Biomed Sci (2006) 13(6):787-96. doi: 10.1007/s11373-006-9107-5

46. Salanova B, Choi M, Rolle S, Wellner M, Luft FC, Kettritz R. Beta2-integrins and acquired glycoprotein IIb/IIIa (GPIIb/IIIa) receptors cooperate in NF-kappaB activation of human neutrophils. J Biol Chem (2007) 282(38):27960-9. doi: 10.1074/jbc.M704039200

47. Duchez AC, Boudreau LH, Naika GS, Bollinger J, Belleannée C, Cloutier N, et al. Platelet microparticles are internalized in neutrophils via the concerted activity of 12-lipoxygenase and secreted phospholipase A2-IIA. Proc Natl Acad Sci U.S.A (2015) 112(27):E3564-73. doi: 10.1073/pnas.1507905112

48. Rousseau M, Belleannee C, Duchez AC, Cloutier N, Levesque T, Jacques F, et al. Detection and quantification of microparticles from different cellular lineages using flow cytometry. Evaluation of the impact of secreted phospholipase A2 on microparticle assessment. PLoS ONE (2015) 10(1):e0116812. doi: 10.1371/ journal.pone.0116812

49. Scherlinger M, Sisirak V, Richez C, Lazaro E, Duffau P, Blanco P. New insights on platelets and platelet-derived microparticles in systemic lupus erythematosus. Curr Rheumatol Rep (2017) 19(8):48. doi: 10.1007/s11926-017-0678-0

50. Uribe-Querol E, Rosales C. Neutrophils in cancer: two sides of the same coin. J Immunol Res (2015) 2015:983698:1-21. doi: 10.1155/2015/983698

51. Boilard E. Platelet-derived nanomedicine targets cancer. Blood (2017) 130(5):561-2. doi: 10.1182/blood-2017-05-786327

Conflict of Interest Statement: The authors declare that the research was conducted in the absence of any commercial or financial relationships that could be construed as a potential conflict of interest.

Copyright (c) 2018 Goldfinger and Lazar. This is an open-access article distributed under the terms of the Creative Commons Attribution License (CC BY). The use, distribution or reproduction in other forums is permitted, provided the original author $(s)$ and the copyright owner are credited and that the original publication in this journal is cited, in accordance with accepted academic practice. No use, distribution or reproduction is permitted which does not comply with these terms 